\title{
LEM-domain proteins are lost during human spermiogenesis but BAF and BAF-L persist
}

\author{
Razan A Elkhatib¹, Marine Paci ${ }^{1,2}$, Romain Boissier ${ }^{3}$, Guy Longepied ${ }^{1}$, Yasmina Auguste $^{1}$, \\ Vincent Achard ${ }^{2,4}$, Patrice Bourgeois' ${ }^{1}$, Nicolas Levy ${ }^{1}$, Nicolas Branger ${ }^{3}$, Michael J Mitchell ${ }^{1, *}$ \\ and Catherine Metzler-Guillemain ${ }^{1,2, *}$ \\ ${ }^{1}$ Aix Marseille Univ, INSERM, GMGF, UMR_S 910, Marseille, France, ${ }^{2}$ APHM Hôpital La Conception, Gynépôle, \\ Laboratoire de Biologie de la Reproduction-CECOS, Marseille Cedex 5, France, ${ }^{3}$ APHM Hôpital La Conception, \\ Service d'Urologie, Marseille Cedex 5, France and ${ }^{4}$ Aix-Marseille Univ, Univ Avignon, CNRS, IRD, IMBE, UMR7263, \\ Marseille France
}

Correspondence should be addressed to M J Mitchell or C Metzler-Guillemain; Email: michael.mitchell@univ-amu.fr or catherine.metzler-guillemain@univ-amu.fr

*(MJ Mitchell and C Metzler-Guillemain are equal senior authors)

\begin{abstract}
During spermiogenesis the spermatid nucleus is elongated, and dramatically reduced in size with protamines replacing histones to produce a highly compacted chromatin. After fertilisation, this process is reversed in the oocyte to form the male pronucleus. Emerging evidence, including the coordinated loss of the nuclear lamina (NL) and the histones, supports the involvement of the NL in spermatid nuclear remodelling, but how the NL links to the chromatin is not known. In somatic cells, interactions between the NL and the chromatin have been demonstrated: LEM-domain proteins and LBR interact with the NL and respectively, the chromatin proteins BAF and HP1. We therefore sought to characterise the lamina-chromatin interface during spermiogenesis, by investigating the localisation of six LEM-domain proteins, two BAF proteins and LBR, in human spermatids and spermatozoa. Using RT-PCR, IF and western blotting, we show that six of the proteins tested are present in spermatids: LEMD1, LEMD2 (a short isoform), ANKLE2, LAP2 $\beta$, BAF and BAF-L, and three absent: Emerin, LBR and LEMD3. The full-length LEMD2 isoform, required for nuclear integrity in somatic cells, is absent. In spermatids, no protein localised to the nuclear periphery, but five were nucleoplasmic, receding towards the posterior nuclear pole as spermatids matured. Our study therefore establishes that the lamina-chromatin interface in human spermatids is radically distinct from that defined in somatic cells. In ejaculated spermatozoa, we detected only BAF and BAF-L, suggesting that they might contribute to the shaping of the spermatozoon nucleus and, after fertilisation, its transition to the male pronucleus.

Reproduction (2017) 154 387-401
\end{abstract}

\section{Introduction}

Spermiogenesis is the post-meiotic phase of spermatogenesis when haploid round spermatids undergo a dramatic transformation into mature elongated spermatozoa. This involves nuclear remodelling, chromatin condensation, replacement of nuclear histones with protamines and formation of an acrosomal cap and a flagellum at opposite poles of the spermatid nucleus. Although the precise mechanisms are not yet fully elucidated, it is certain that these processes are in part coordinated by interactions between the nuclear envelope (NE) and specialised cytoskeletal elements of the spermatid, the acroplaxome and the manchette (Kierszenbaum \& Tres 2004).

The NE of eukaryotic cells is composed of the two nuclear membranes, the $\mathrm{NL}$ and the nuclear pore complexes (NPCs) that create channels between the nucleoplasm and the cytoplasm. The outer nuclear membrane (ONM) is continuous with the endoplasmic reticulum (ER), whereas the inner nuclear membrane (INM) is lined on its nucleoplasmic face by the $\mathrm{NL}$, a peripheral network of type $\mathrm{V}$ intermediate filaments, called lamins, involved in chromatin organisation, cell cycle regulation, DNA replication, cell differentiation, gene expression and apoptosis (Burke \& Stewart 2013). During spermiogenesis in human and mouse, the NL is composed exclusively of B-type lamins, and retreats from the anterior to the posterior pole as the acrosome spreads and the histones are removed from the chromatin (Alsheimer et al. 2004, De Vries et al. 2012, Elkhatib et al. 2015). 
The NL is known to connect to the cytoskeleton through the interaction of SUN and KASH proteins that span the nuclear membranes. In spermatids, the proteins SUN3, SUN4 and SUN5 have a localisation coincident with the lamins (Göb et al. 2010, Calvi et al. 2015, Yassine et al. 2015). In mice lacking SUN4, spermatids do not elongate, and spermatozoa have round heads (globozoospermia-like) (Calvi et al. 2015, Pasch et al. 2015). Biallelic loss-of-function mutations in SUN5 have been found in men with acephalic spermatozoa syndrome (Zhu et al. 2016, Elkhatib et al. 2017). True globozoospermia is observed in mice and men lacking DPY19L2, an INM protein localised under the acrosome (Harbuz et al. 2011, Koscinski et al. 2011, Pierre et al. 2012). In mice lacking DPY19L2, the acrosome detaches, elongation does not occur and lamins remain throughout the nuclear periphery of spermatozoa (Pierre et al. 2012, Yassine et al. 2015). There is therefore good evidence that the NL has central roles in shaping functional spermatozoa.

In contrast, little is known about how the NL interacts with the chromatin during spermiogenesis, despite the identification of proteins that form links between the NL and the chromatin in somatic cells: Lamin B receptor (LBR), members of the LEM-domain (the lamina-associated polypeptide 2, Emerin, MAN1 domain) protein family and barrier-to-autointegration factor (BAF) (Goldman et al. 2002, Gruenbaum et al. 2005, Schirmer \& Foisner 2007). LBR was the first integral membrane protein of the INM to be identified (Worman et al. 1988). LBR binds to lamin B1 and links the lamina to the chromatin through an interaction with the HP1-type heterochromatin proteins (Ye \& Worman 1994, Ye et al. 1997). Human LEM-domain proteins are a heterogeneous family of mainly nuclear proteins that share a conserved $\sim 40$ amino acid domain, the LEMdomain, named after three LEM-domain proteins shown to bind BAF: LAP2, EMERIN and MAN1 (aka LEMD3) (Furukawa 1999, Cai et al. 2001, Lee et al. 2001, Shumaker et al. 2001, Mansharamani \& Wilson 2005). In addition to the founding proteins, four other human LEMdomain encoding genes have been described: LEMD1, with testis-predominant transcription (Yuki et al. 2004), LEMD2, required for nuclear integrity (Brachner et al. 2005), ANKLE2, a regulator of BAF phosphorylation with a role in post-mitotic nuclear envelop formation (Lee \& Wilson 2004, Asencio et al. 2012) and ANKLE1, an endonuclease possibly involved in DNA repair (Brachner et al. 2012).

BAF, a conserved metazoan chromatin protein (Lee \& Craigie 1998) plays a key role in post-mitotic nuclear assembly (Margalit et al. 2007). It forms homodimers that can simultaneously bind dsDNA molecules and a LEM-domain (Shumaker et al. 2001, SeguraTotten et al. 2002). BAF is expressed widely, but has a paralogue, barrier-to-autointegration factor-like (BAF-L) that is expressed predominately in testis and pancreas
(Tifft et al. 2006, Margalit et al. 2007). Human BAF-L and BAF share $40 \%$ amino acid identity. BAF-L was described as specific to mammals (Margalit et al. 2007), but recent additions to the databases indicate that BAF-L is specific to vertebrates. Unlike BAF, BAF-L does not bind DNA. BAF-L does form heterodimers with BAF, and it may thus modulate BAF chromatin functions in testis and pancreas (Tifft et al. 2006).

Except for LBR and LAP2 isoforms, none of these proteins has been studied during mammalian spermiogenesis. LBR has been localised to the nuclear periphery of elongating spermatids in the rat, where a role in chromatin remodelling during spermiogenesis has been proposed based on the detection, in vitro, of an interaction with protamine 1 (Mylonis et al. 2004). The LAP2 isoforms have also been studied in the rat, where LAP2 $\beta$ predominates in spermatids, but only LAP2 $\alpha$ persists in mature spermatozoa (Alsheimer et al. 1998). Thus, as a first step towards defining how the NL interfaces with the chromatin during spermiogenesis, we have characterised the expression of LBR, BAF, BAF-L and six LEM-domain proteins in human spermatids and spermatozoa.

\section{Materials and methods}

\section{Patients}

Sperm samples were obtained from fourteen normospermic men who consulted at our reproduction centre or gamete bank (CECOS - Centre d'Etude et de Conservation des Oeufs et du Sperme) in Marseilles: 10 men consulted for couple infertility (9 primary and 1 secondary infertility), four men were fertile sperm donors (Table 1).

Testicular samples came from four patients with brain death, who were 21, 31, 50 and 65 years old. Testicular samples were obtained within a protocol, approved by the French Research Minister, for the collection of human tissue for use in research. We declared our protocol through the Biomedicine Agency in January 2013. Testes were recovered during multi-organ retrieval for transplantation while the patient was under extracorporeal circulation and respiratory assistance. All patients had normal spermatogenesis based on histology analysis and retrieval of numerous spermatozoa after testis dilaceration and one of the four patients had children (T011400063, T011400051, T011400071 and T011500055).

\section{Semen and testicular samples}

Semen was collected via masturbation after a period of sexual abstinence of 2-6 days. After $30 \mathrm{~min}$ of liquefaction, semen analysis was performed according to the WHO criteria (WHO Association 2009), and according to the French David classification for the morphology analysis (Auger et al. 2016). Sperm was diluted in cryoprotectant medium (Spermfreeze; JCD, La Mulatière, France) and transferred into straws (Cryo Bio System, Saint Ouen sur Iton, France). Straws were then suspended in vapour-phase nitrogen before being stored in liquid nitrogen until use. All patients gave an informed consent 
Table 1 Sperm parameters of patients whose spermatozoa were used for RT-PCR, western blot (WB), immunofluorescence analysis (IF) and selection procedures.

\begin{tabular}{lcccccc}
\hline Patients & GT number & Spz $(\mathrm{M} / \mathrm{mL})$ & Motility $(\mathrm{a}+\mathrm{b} / \mathrm{c} / \mathrm{d})^{*}$ & Vitality $(\%)$ & Normal forms** $(\%)$ & Technics performed on spermatozoa \\
\hline $1^{\mathrm{F}}$ & R 011300032 & 84 & $35 / 20 / 45$ & 78 & 39 & RT-PCR \\
$2^{\mathrm{F}}$ & R 011300029 & 160 & $50 / 10 / 40$ & 70 & 37 & RT-PCR, IF \\
3 & R 010900491 & 102 & $45 / 20 / 35$ & 85 & 45 & RT-PCR, IF, WB \\
$4^{\mathrm{Sl}}$ & R 010900544 & 150 & $50 / 20 / 30$ & 80 & 41 & RT-PCR \\
5 & R 010900563 & 109.6 & $60 / 10 / 30$ & 80 & 39 & RT-PCR \\
6 & R 01090026 & 44 & $60 / 20 / 20$ & 64 & 20 & RT-PCR \\
7 & R 01090040 & 33.6 & $40 / 10 / 50$ & 60 & 22 & RT-PCR \\
8 & R 010900236 & 63.4 & $30 / 25 / 40$ & 81 & 20 & RT-PCR \\
9 & R 010900505 & 92 & $25 / 45 / 30$ & 82 & 54 & IF \\
10 & R 011500066 & 135 & $30 / 10 / 60$ & 65 & 22 & WB \\
$11^{\mathrm{F}}$ & R 011500071 & 130 & $30 / 10 / 60$ & 59 & 32 & WB \\
12 & R 010900549 & 195 & $60 / 10 / 30$ & 85 & 53 & WB \\
13 & R 010900409 & 259,8 & $30 / 10 / 60$ & 82 & 53 & WB \\
14 & R 010900214 & 159 & $35 / 10 / 55$ & 70 & 34 & WB \\
\hline
\end{tabular}

FFertile patients; ${ }^{\mathrm{SI}}$ secondary infertility; ${ }^{*} \mathrm{WHO}$ criteria; ${ }^{* *}$ normal forms (David criteria).

for the conservation of the remnant sperm in the Germetheque biobank and their use in studies on human fertility in accordance with the Helsinki Declaration of 1975 on human experimentation. The Germetheque Scientific Committee approved the present study design. All sperm samples came from patients with normal sperm parameters according to the WHO criteria (Table 1).

Testicular cells were fixed in $4 \%$ paraformaldehyde in phosphate buffered saline (PBS) and frozen, from the four patients (T011400063, T011400051, T011400071 and T011500055) prior to use.

\section{Spermatozoa RNA extraction}

Following storage in liquid nitrogen, sample straws were thawed and the sperm was washed twice in $2 \mathrm{~mL}$ of PBS, and then suspended in round cell lysis buffer $(0.1 \%$ SDS, $0.5 \%$ Triton $\mathrm{X}-100$ in RNase free $\left.\mathrm{H}_{2} \mathrm{O}\right)$. RNA was extracted with $1 \mathrm{~mL}$ of Tripure (Roche) and precipitated with $20 \mu \mathrm{g}$ of glycogen as carrier. RNAs were treated with 10 units of DNase $\mathrm{I}$, at room temperature for $10 \mathrm{~min}$, in $1 \times$ reverse transcriptase buffer with $10 \mathrm{mM}$ DTT and 20 units of Protector RNAse inhibitor (Roche).

\section{RT-PCR and quality control of spermatozoa RNA extracts}

Before reverse transcription, RNA was purified on chromaspin 100 (Clontech) or Nucleospin RNA XS columns (Macherey Nagel). Concentration was determined using a nanodrop ND-1000 spectrophotometer (NanoDrop Technologies, Wilmington, DE, USA). RNAs (400 ng) were reverse transcribed in a $20 \mu \mathrm{L}$ reaction with random nanomers $(75 \mathrm{pmol})$ and Expand reverse transcriptase (Roche). The resulting cDNA was diluted to $40 \mu \mathrm{L}$ with water and $1 \mu \mathrm{L}$ used in subsequent polymerase chain reaction (PCR) amplification with Q5 HighFidelity DNA Polymerase (New England Biolabs).

Control PCRs were carried out with standard Taq polymerase. We checked for the presence of spermatid RNA derived cDNAs by amplifying the protamine 1 transcript with primers $01680 / \mathrm{o} 1681$ annealed at $60^{\circ} \mathrm{C}$. We checked for the lack of contaminating round cell RNA by PCRs using a triplex reaction with primers for PTPRC (CD45), KIT and CDH1 which are positive markers for leukocytes, early testicular germ cells and epithelial cells respectively (Lambard et al. 2004). Triplex primers and concentrations: PTPRC (310 bp) o4609/o4610, $300 \mathrm{nM}$; c-Kit (237 bp) - o4611/o4612, $500 \mathrm{nM}$; CDH1 136 bp - o4613/o4614, 500 nM. PCR programme $94^{\circ} \mathrm{C} 2 \mathrm{~min}, 94^{\circ} \mathrm{C} 30 \mathrm{~s}, 60^{\circ} \mathrm{C} 40 \mathrm{~s}, 72^{\circ} \mathrm{C} 20 \mathrm{~s} 40$ cycles, $72^{\circ} \mathrm{C} 5 \mathrm{~min}$.

LEM-domain protein transcripts were amplified with Q5 Taq polymerase (New England Biolabs) using the PCR conditions described in the product information. The primer pairs and their annealing temperature for each transcript are as follows: LEMD1: 04426/04427 - 66 ${ }^{\circ} \mathrm{C}$, LEMD2-3': 04092/o4093 68 ${ }^{\circ} \mathrm{C}$, LEMD2-5': 04965/04966 - 69 ${ }^{\circ} \mathrm{C}$, LEMD3-3': 05023/ o4491 - 66 ${ }^{\circ} \mathrm{C}$, LEMD3-5': 05024/05026 - 67 ${ }^{\circ} \mathrm{C}$, EMERIN-3': o5097/05098 - 69 ${ }^{\circ} \mathrm{C}$, EMERIN-5': 05095/05096 - 67 ${ }^{\circ} \mathrm{C}$, ANKLE1-3': o5027/04493 - 67 ${ }^{\circ} \mathrm{C}$, ANKLE1-5': 05028/ o5029 - 72 ${ }^{\circ} \mathrm{C}$, ANKLE2-3': 04495/04496 - 68 ${ }^{\circ} \mathrm{C}$, ANKLE25': o5111/o5112 - 70 C, ANKLE2_A1-64: o4527/o4528 $71^{\circ} \mathrm{C}$, LAP2-5': o5101/05103 - $68^{\circ} \mathrm{C}$ LAP2 $\alpha \quad 3^{\prime}:$ o $4087 /$ o4088 - $64^{\circ} \mathrm{C}$, LAP2 $\beta$ 3': o5099/05100 - 68 ${ }^{\circ} \mathrm{C}$, LAP2 $\beta-5^{\prime}$ : o4087/04090 - 64 ${ }^{\circ} \mathrm{C}$, BAF: o4094/o4095 - 69 ${ }^{\circ}$, BAF-L: 04096/04097 - 69 ${ }^{\circ} \mathrm{C}$, LBR-3': o4667/04668 - 60 ${ }^{\circ} \mathrm{C}$, LBR-5': o4669/o4671 - $64^{\circ} \mathrm{C}$, musLEMD1: o4435/o4434 - $67^{\circ} \mathrm{C}$, musBAF-L: o4522/o4523 - 67 ${ }^{\circ} \mathrm{C}$, musHMBS: o2216/o2217 $67^{\circ} \mathrm{C}$, PRM1: 01680/01681 - 60 ${ }^{\circ} \mathrm{C}$. PRM1, a spermatidspecific spermatozoa-retained transcript was included as a positive control for spermatozoa RNA. The Q5 GC-enhancer additive was used for all PCRs except for LBR. (Sequences of primers are provided in Supplementary Table 1, see section on supplementary data given at the end of this article.)

\section{Constructs to express tagged proteins}

To express fusion proteins tagged with either 3xc-Myc (Мyc) or $3 x$ Flag (Flag), the coding region for each protein was amplified by PCR from human testis CDNA, using specific primers with restriction sites added at the $5^{\prime}$ end. The PCR products were digested at these added sites and ligated to a vector cut with the same enzymes. The vectors were modified pcDNA3.1 
vector (Life Technologies) carrying either an N-terminal tag between Nhel and HindIII sites or a C-terminal tag between BamHI and Xbal sites. The primers used are shown in Supplementary Table 1. Flag-ANKLE2, primers: o4573/o4710, cloning sites: Kpnl and BamHI. Flag-ANKLE2- $\Delta 1-64$, primers: o4542/o4710, cloning sites: Kpnl and BamHI. LEMD2-myc and LEMD2_A115-259-myc, primer: o5322/o5323, cloning sites: HindIII and Kpnl. BAF-Flag, primers: 04388/o4399, cloning sites: Kpnl and BamHI. Flag-BAF-L, primers: o5186/ 04663, cloning sites: Kpnl and Xhol. myc-LEMD1, primers: o4661/o4659, cloning sites Kpnl and Xhol. myc-Emerin, primers: 04579/o4580, cloning sites: BamHI and Xhol. mycLAP2 $\beta$, primers: o5022/o4615, cloning sites: BamHI and Xhol. All constructs used were confirmed to have the expected sequence by determining the sequence of the full insert and tag.

\section{Cell culture and transfection}

HeLa cells were cultured according to standard procedures. Cells were transfected in two-well Lab-tek chambers using jetPRIME short-DNA transfection protocol (Polyplustransfection) and 500 ng of plasmid DNA according to the manufacturer's instructions. The medium was replaced after $4 \mathrm{~h}$ of incubation with the transfection mix.

\section{Immunocytochemistry}

Immunocytochemistry was performed on spread spermatozoa and/or testicular germ cells.

Thawed spermatozoa were washed two times in PBS, fixed in $2 \%$ formaldehyde in PBS for 10 min, washed twice in PBS and spread onto polylysine-coated slides by cytospin (Shandon). Testicular cells were fixed with $2 \%$ formaldehyde in PBS for $10 \mathrm{~min}$ after disaggregation of testis fragments, washed in PBS and pellets frozen. Testicular cell pellets were thawed and spread onto polylysine slides by cytospin (Shandon) as previously described (Metzler-Guillemain \& Guichaoua 2000). Slides were fixed $5 \mathrm{~min}$ in $4 \%$ formaldehyde in PBS, rinsed in PBS and permeabilised using $0.1,0.3$ or $0.5 \%$ Triton X-100, 3\% normal goat serum in PBS for $30 \mathrm{~min}$. Slides were blocked with $1 \%$ BSA, $7 \%$ normal goat serum in PBS for $30 \mathrm{~min}$. They were then incubated for $30 \mathrm{~min}$ with lectins (Lectin PNA Alexa Fluor 594 conjugates, L-21409 Molecular Probes) at a dilution of 1:600 in PBS to mark the acrosome. After washes in PBS under gentle agitation, slides were incubated one to two hours in a moist chamber at $37^{\circ} \mathrm{C}$ with primary antibodies. After several washes in PBS, detection was performed using Alexa Fluor secondary antibodies (Invitrogen) at dilutions recommended by manufacturers for $45 \mathrm{~min}$ at $37^{\circ} \mathrm{C}$. Slides were then rinsed twice in PBS and mounted with $25-75 \mathrm{ng} / \mathrm{mL}$ DAPI in Vectashield mounting medium for microscope analysis. Negative controls without the primary antibody gave no signal for any of the secondary antibodies used. The slides were analysed using the Zeiss ApoTome.2 microscope (Zeiss) equipped with an AxioCam $M R m$ camera. Images were captured and merged with the ZEN software, and were treated using ImageJ software. Phase contrast overlay of ANKLE2 immunofluorescent labelling shows that cell morphology is preserved by this protocol (Supplementary Fig. 1).

\section{Antibodies}

The affinity of antibodies for their target was validated for immunofluorescence (IF) analysis using HeLa cells transfected with a construct overexpressing a tagged version of the target protein, except for those against LEMD3, already shown by the supplier to label the nuclear periphery in HeLa cells (Supplementary Fig. 2). All antibodies used were monoclonal or immunogen affinity-purified polyclonal and gave the expected labelling pattern in somatic cells in disaggregated testes: nuclear periphery for LEMD2, LEMD3, Emerin, LAP2 $\beta$, LBR and BAF; ER for ANKLE2; faint or no labelling for LEMD1 and BAF-L (only spermatid nuclei labelled). We provide representative images of single large fields obtained for each antibody to show the labelling of germ cells and somatic cells observed together in disaggregated testes (Supplementary Fig. 3).

The antibodies used were rabbit anti-LEMD1 (IF dilution: 1/100, SAB3500644 Sigma), rabbit anti-LEMD2 specific N-terminus (IF dilution: 1/100, HPA017340 Sigma), rabbit anti-LEMD2 specific C-terminus (IF dilution: 1/50, ab89866 Abcam), mouse anti-LEMD3 (IF dilution: 1/50, ab123973 Abcam), mouse anti-EMERIN (IF dilution: 1/100, NCLEMERIN Leica), mouse anti-EMERIN (IF dilution: 1/100, Sigma AMAb90560), rabbit anti-ANKLE2 (IF dilution: 1/100, Asencio et al. 2012), rabbit anti-LAP2 beta (IF dilution: 1/50, HPA008150 sigma), rabbit anti-BAF (IF dilution: 1/600 ab129184 Abcam), rabbit anti-BAF-L (IF dilution: 1/100, HPA042635 Sigma), rabbit anti-BAF-L (IF dilution: 1/200, ab122950 Abcam), rabbit anti-LBR (IF dilution: 1/500, ab32535 Abcam), mouse anti-Flag (IF dilution: 1/100, F1804 Sigma), mouse anti-c-MYC (IF dilution: 1/100, sc40 Santa Cruz), rabbit anti- $\alpha$ tubulin (WB dilution: 1/1000, ab15246 Abcam) and anti-GRP94 (IF dilution: 1/400, ab210960) (Supplementary Table 2).

The immunogen peptide used for pre-absorption of antiBAF (within amino acids 1-45) was custom synthesised (Proteogenix, France). The immunogen peptide for BAF-L (aa 12-252) was expressed as a fusion protein with the chitin binding protein in Escherichia coli and purified on a chitin column, following the protocol of the Impact Kit (New England Biolabs), except that the BAF-L fusion protein was eluted with $8 \mathrm{M}$ urea and then dialysed against PBS. The BAF-L coding region was amplified with primers o5350/05351 and cloned between the Ndel and Xhol sites of the pMXB10 vector (New England Biolabs). For preabsorption, prior to use in IF, $100 \mu$ l of a $1 / 100$ dilution of anti-BAF or anti-BAF-L in PBS, $1 \%$ BSA was incubated with $5 \mu \mathrm{g}$ of its immunogen peptide, overnight at $4^{\circ} \mathrm{C}$.

\section{Protein extraction and western blot analysis}

Protein was prepared from $12 \times 10^{6}$ spermatozoa which were separated from round cells as for RNA extraction, and then lysed on ice for $30 \mathrm{~min}$ in $100 \mu \mathrm{L}$ of $0.5 \%$ SDS, $50 \mathrm{mM}$ Tris. $\mathrm{HCl}$, pH 8.0, $5 \mathrm{mM}$ EDTA, $50 \mathrm{mM}$ DTT, $2 \times$ complete proteinase inhibitor cocktail (Roche), followed by $30 \mathrm{~s}$ of 
sonication at high setting in a Bioruptor Standard (Diagenode). The effectiveness of the round cell lysis is illustrated by the absence of a signal for Emerin, despite the strong signal in whole testis (Supplementary Fig. 4). Emerin is strongly detected in testicular somatic cells, but we did not detect it by IF in spermatids or spermatozoa. For testis lysates, $60 \mathrm{mg}$ of tissue was dissociated in $300 \mathrm{~mL}$ of lysis buffer (1 M Tris. $\mathrm{HCl}, \mathrm{pH} 7.5$, $5 \mathrm{M} \mathrm{NaCl}, 0.1 \mathrm{mM}$ EGTA, $10 \%$ Triton) using ceramic beads in a Magnalyser (Roche), followed by $30 \mathrm{~min}$ on ice and $3 \times 30$ s of sonication at high setting in a Bioruptor Standard (Diagenode). For migration, lysate from approximately 2 million spermatozoa or $40 \mu \mathrm{g}$ of testis protein was mixed with $2 \times$ Laemmli sample loading buffer (Sigma Aldrich) with 5\% $\beta$-mercaptoethanol, heated to $95^{\circ} \mathrm{C}$ for $5 \mathrm{~min}$ and subjected to SDS-PAGE. Proteins were blotted on to nitrocellulose with a pore size of $0.45 \mu \mathrm{m}$ (Emerin) or $0.2 \mu \mathrm{m}$ (BAF, BAF-L).

\section{Results}

\section{Spermatid transcript analysis using spermatozoa $R N A$}

To characterise gene expression of NL-associated proteins (LBR, LEM-domain proteins, BAF and BAF-L) during human spermiogenesis, we first used RT-PCR to detect the $5^{\prime}$ and $3^{\prime}$ end of the coding region of transcripts, in spermatozoa RNA from five normospermic men: two fertile men and three men from infertile couples. RT-PCR detected transcripts for Emerin, LEMD1, LEMD2, ANKLE2, LAP2 $\alpha$, LAP2 $\beta$ and BAF-L in all tested RNA samples (Fig. 1), but in the case of LEMD2 only the 3' end of the coding region was detected, indicating that the only transcript present for LEMD2 in spermatids lacks a part of the $5^{\prime}$ coding region present in the widely expressed form. No transcripts were detected for LBR, LEMD3 or ANKLE1 in any sample (Fig. 1).

BAF transcripts were detected in one RNA sample R010900491 but not in the other four, suggesting that they are normally absent from spermatozoa (Fig. 1). BAF is encoded by the BANF1 gene, and has five retroposed homologues in the genome. We therefore investigated the nature of the BANF1 cDNA product amplified from R010900491 by sequencing and revealed it to be identical to the BANF1 locus, excluding the possibility that it was derived from one of the BANF1 retroposons. In addition, we did not amplify the same cDNA product from the genomic DNA of R010900491, excluding the possibility that R010900491 carries a recently integrated BANF1 retroposon with $100 \%$ nucleotide identity to $B A N F 1$. The individual in whose sperm sample we detected BAF transcripts is normospermic and his sperm does not have an exceptional morphology or motility profile. He is nevertheless in an infertile couple, and it will now be important to define the relationship between BAF transcript retention in spermatozoa and gamete quality. We conclude that the BANF1 transcript can persist

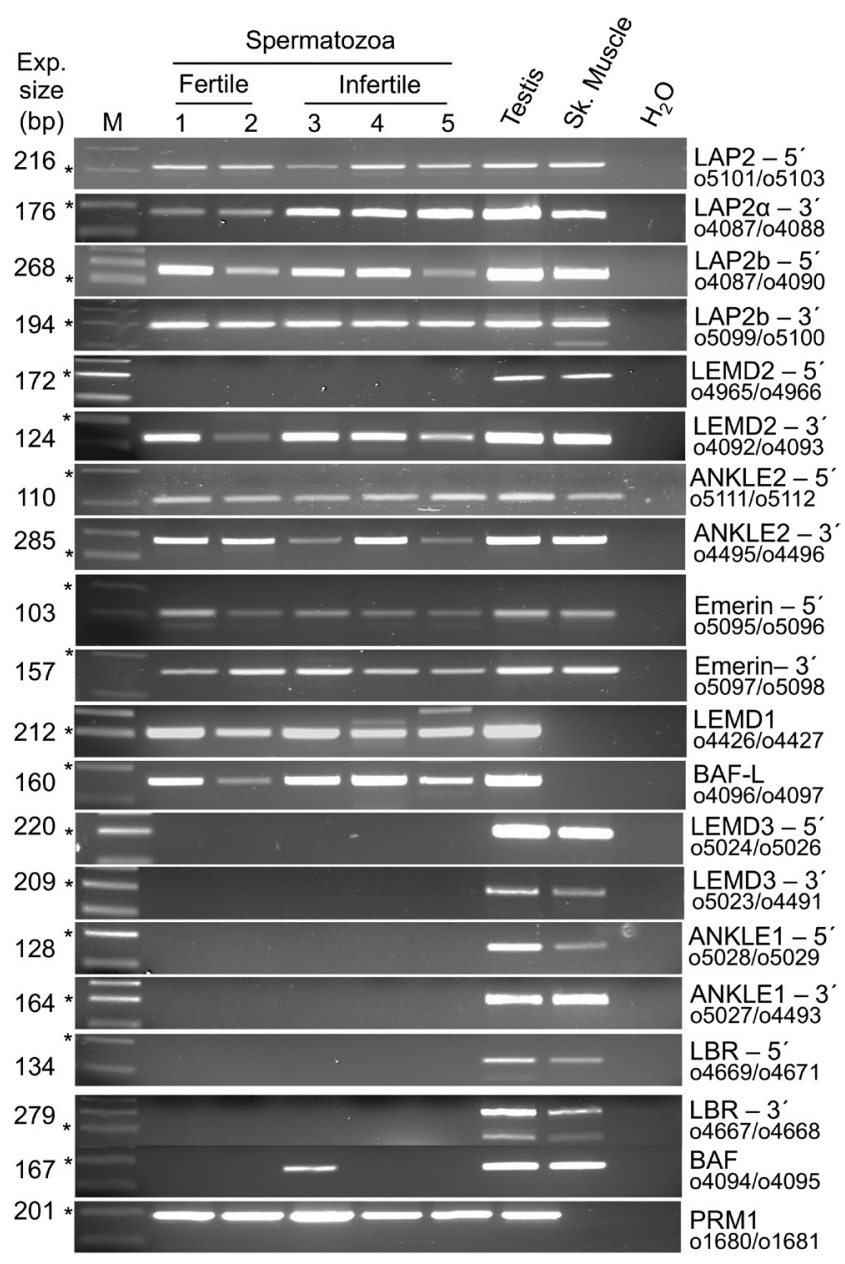

Figure 1 RT-PCR amplification of transcripts coding LEM-domain proteins in human from total spermatozoa RNA, testis RNA and skeletal muscle RNA. RT-PCR analysis of the 5' and 3' ends of the coding region were performed separately for all tested transcripts, except for the short two exon coding regions of BAF and BAF-L, which were tested with a single RT-PCR assay. RT-PCR products are shown migrated on a 3\% agarose gel. Spermatozoa RNAs were extracted from samples from individuals 1 to 5 in Table 1 . The protein encoded by the target transcript and the primer pairs used are indicated at the right of the gel. The known spermatid transcript for protamine 1 (PRM1) was amplified as a positive control. The expected size of each amplicon is shown at the left of the gel. The ladder is $1 \mathrm{~kb}$ Plus DNA Ladder (Life Technologies), and the $200 \mathrm{bp}$ band is indicated with an $\left(^{*}\right)$.

in spermatozoa in a minority of cases, but whether this is related to increased RNA stability, epigenetic variation or the quality of spermatogenesis remains to be elucidated.

\section{$B A F-L$ and LEMD1 transcripts coincide with spermatids in immature mouse testis}

Having shown that transcripts for the testis-predominant genes BANF2 and LEMD1 were present in human spermatids, we next investigated transcription from these genes during the first wave of postnatal spermatogenesis in the mouse. We found that transcripts 


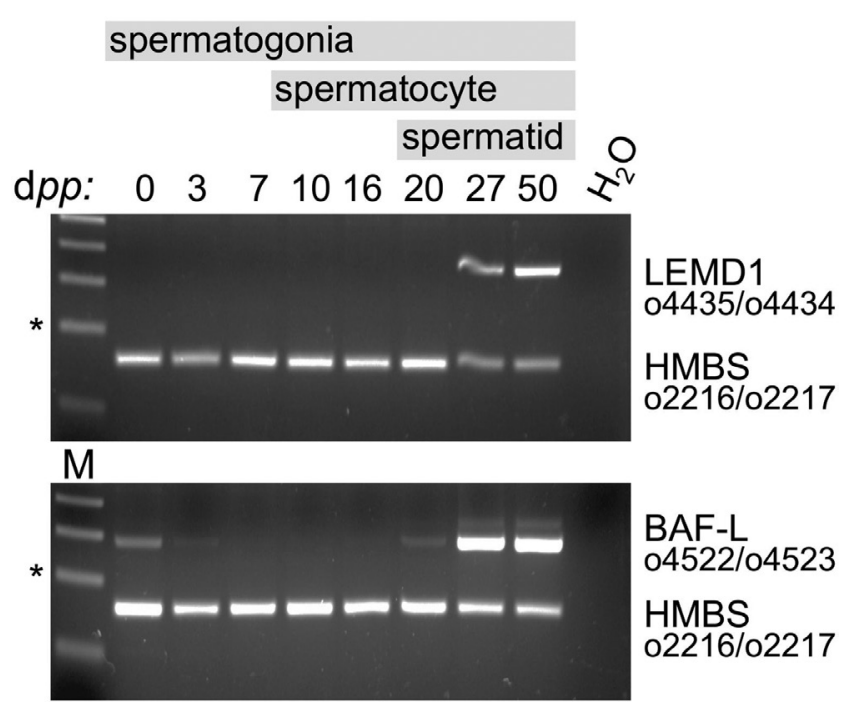

Figure 2 RT-PCR analysis of mouse transcripts for LEMD1 and BANF2 on RNA extracted from staged mouse testis of different postnatal ages (dpp: days post partum). The expected germ cell content is indicated above the gel by the grey bars. Amplicons from LEMD1 or BAF-L transcripts were co-amplified with amplicons from the control HMBS transcript by RT-PCR, and show that LEMD1 and BANF2 transcripts predominate during mouse spermiogenesis. The proteins encoded by transcripts and the primers pair used are indicated at the right of the gel. The expected sizes of amplicons are shown at the left of the gel. The ladder is $1 \mathrm{~kb}$ Plus DNA Ladder (Life Technologies), and the 200 bp band is indicated with an $\left(^{*}\right)$.

for both genes were detected only at later steps (after $20 \mathrm{dpp}$ ) when spermatids first appear in the testis (Fig. 2). We conclude that BAF-L and LEMD1 transcripts predominate in spermatids in mouse and human.

\section{Alternative transcript for ANKLE2 in spermatids}

For ANKLE2, we detected a transcript (ANKLE2__1-64) corresponding to several testis ESTs with an alternative first exon situated within the first intron (e.g. HY008086) (Fig. 3A). We amplified ANKLE2_ $\Delta 1-64$ from all five spermatozoa RNA samples (Fig. 3B), and from total RNA of testis and brain, but not small intestine, skeletal muscle, prostate or thymus (Fig. 3C). In the mouse, no EST corresponding to this transcript has been described, and we did not detect a homologous transcript from the mouse Ankle2 gene by RT-PCR with primers from candidate alternative first exons in intron 1 defined by splice donor site prediction (data not shown). We amplified as a single amplicon and then sequenced the full coding region of the ANKLE2 $\triangle 1-64$ transcript from human testis RNA and deposited its sequence in Genbank (accession KY056762). The ANKLE2_ 1 1-64 transcript encodes an ANKLE2 isoform lacking the $\mathrm{N}$-terminal 64 amino acids that encode the transmembrane domain of the full-length isoform which are replaced by the short peptide of five amino acids ${ }^{1} \mathrm{MWRSE}^{5}$.
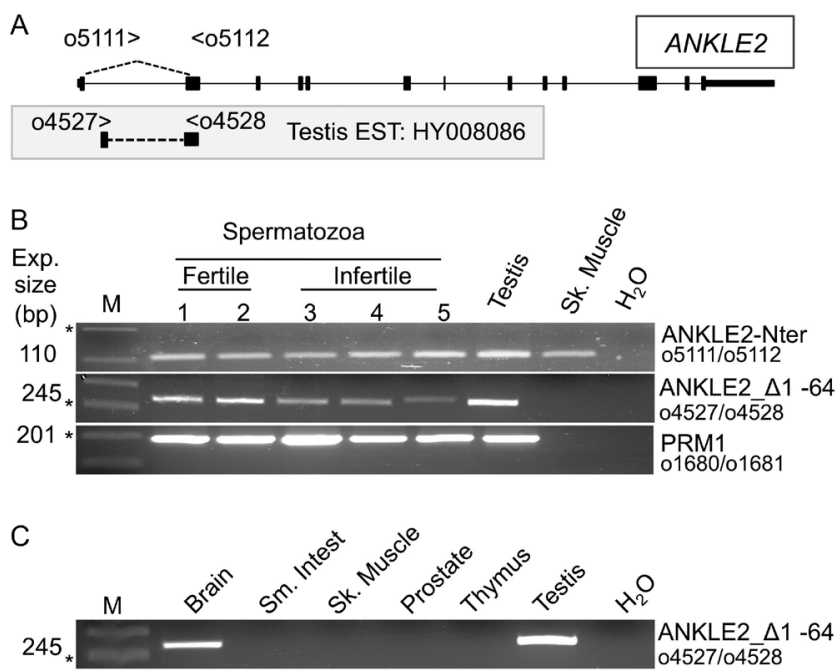

Figure 3 An alternative ANKLE2 transcript encoding ANKLE2_ $\triangle 1-64$ is present in spermatids. (A) Schematic representation of full-length ANKLE2 isoform described in databases, and a testis EST (HY008086) that includes an alternative first exon in intron 1. (B) Specific RT-PCR analysis of the human transcripts encoding the two ANKLE2 isoforms from spermatozoa RNA (individuals $1-5$ in Table 1), testis RNA and skeletal muscle RNA. (C) RT-PCR analysis of the novel alternative transcript ANKLE2_ $\triangle 1-64$ in six tissues: brain, small intestine, skeletal muscle, prostate, thymus and testis. (B and C) PCR products were migrated on $3 \%$ agarose gel. The protein encoded by the target transcripts and the primer pairs used are indicated at the right of the gel. The expected size of amplicon is shown at the left of the gel. The ladder is $1 \mathrm{~kb}$ plus (Life Technologies), and the $200 \mathrm{bp}$ band is indicated with an $\left(^{*}\right)$.

\section{ANKLE2_A1-64 does not localise to the ER in HeLa cells}

The full-length ANKLE2 protein has been localised to the nuclear periphery and ER (Asencio et al. 2012). To test the intracellular localisation of ANKLE2_ $\Delta 1-64$, we transfected HeLa cells with plasmids designed to express $\mathrm{N}$-terminus flag-tagged versions of the full-length ANKLE2 and ANKLE2_ $\triangle 1-64$, under control of the CMV promoter. Following transfection, Flag-ANKLE2 had a granular aspect throughout the cytoplasm that we show co-localises with the ER marker GRP94, consistent with the ER localisation described previously for ANKLE2 (Asencio et al. 2012). In contrast Flag-ANKLE2_A1-64 was more homogeneously distributed throughout the cytoplasm, and did not coincide with GRP94 (Fig. 4A). We conclude that the N-terminal 64 aa of ANKLE2, which contain the TM, are required to locate ANKLE2 to the ER in HeLa cells.

\section{ANKLE2 localises to the ER in round spermatids}

We investigated the localisation of ANKLE2 during spermiogenesis by immunofluorescent analysis of testicular germ cells from four men and ejaculated spermatozoa from three men. An ANKLE2 signal was 
A

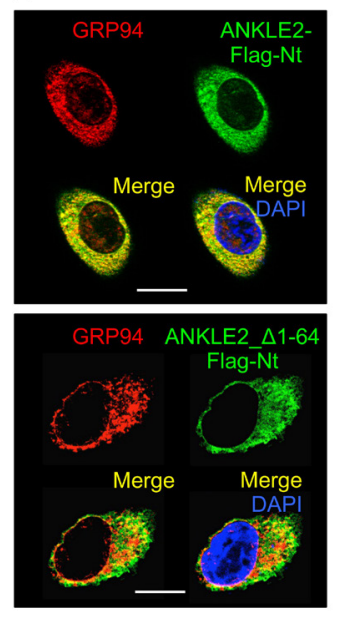

B

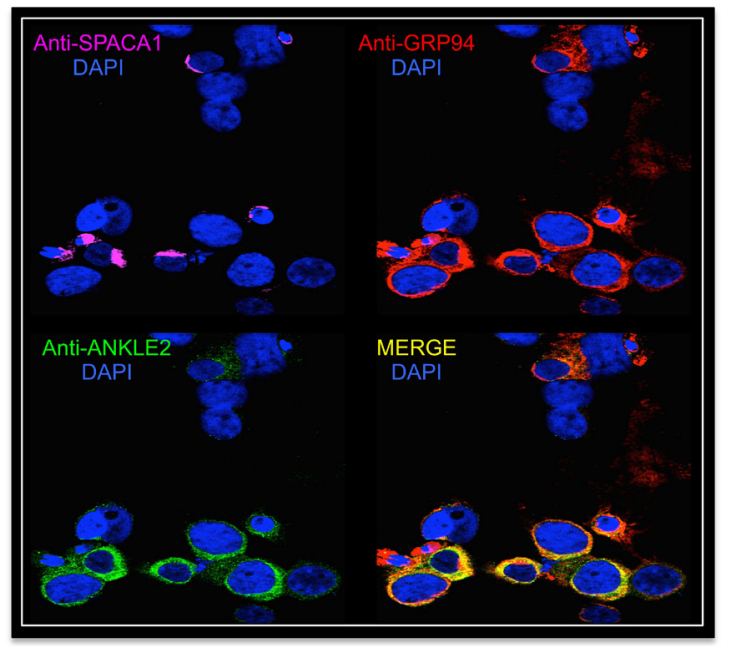

Figure 4 ANKLE2 full-length isoform, but not ANKLE2_A1-64, co-localises with the ER marker GRP94 in HeLa cells and in spermatids. (A) Expression of ANKLE2-Flag and ANKLE2_A1-64-Flag (green) in HeLa cells, showing a granular aspect throughout the cytoplasm for ANKLE2 full length and GRP94 (red), with a strong overlap between ANKLE2 full length and GRP94 (yellow in MERGE photos). On the contrary,

ANKLE2_A1-64 shows a more homogeneous cytoplasmic distribution and little overlap with the GRP94 signal. (B) Immunolocalisation of ANKLE2 on human spermatids, testicular spermatozoa and somatic cells. Spermatids and spermatozoa are identified by the labelling of acrosomes with an anti-SPACA1 antibody (violet). Extensive overlap of ANKLE2 (green) and GRP94 (red) signals is seen in round spermatids (yellow in MERGE), reduced overlap in elongated spermatids and no labelling in testicular spermatozoa. DNA is counterstained with DAPI (blue). Scale bar is $10 \mu \mathrm{m}$. detected throughout human spermiogenesis, in the cytoplasm of round spermatids, elongating spermatids and testicular spermatozoa, but was not visible in ejaculated spermatozoa. In round spermatids, it presented as a granular cytoplasmic signal, consistent with the known localisation of ANKLE2 to the ER (Fig. 4B). We confirmed ER localisation for ANKLE2 in round spermatids, by showing that the signal co-localises with the ER lumen protein GRP94 (Fig. 4C). In elongating spermatids, however, there was no longer a perfect coincidence of GRP94 and ANKLE2 signals, a possible reflection of the distinct localisation of ANKLE2 (ER cytoplasmic surface) and GRP94 (ER lumen). We saw no evidence of the more diffuse cytoplasmic staining that might correspond to the ANKLE2_ $\triangle 1-64$ isoform that lacks the domain necessary for ER localisation (Fig. 4B and C).

\section{LEMD2 transcript in spermatids encodes a short isoform}

To identify the LEMD2 transcript present in human spermatids, we initially screened testis and spermatozoa RNA with RT-PCR assays based on ESTs in the databases that lack the first coding exon of LEMD2 (DC315891, DC367547, BI755923, DB028937 and DC389488), but no product was amplified from testis T011400071 or spermatozoa RNA (data not shown). We next amplified the entire LEMD2 coding region from testis RNA and observed a doublet, a band of the expected size $(1.5 \mathrm{~kb})$ and a smaller band (1.1 kb) (Fig. 5A). We cloned and sequenced thesefragments. The larger fragment contained the full coding region as predicted while the smaller fragment contained two cDNAs created by alternative splicing from a cryptic splice donor site immediately following codon 114 (c.346) in exon 1, to either exon 2 (frameshift) or to exon 3 (non-frameshift) (Fig. 5A). Using specific RT-PCR assays for each transcript we found that both alternatives are present in spermatozoa RNA (shown for the non-frameshift transcript in Fig. 5B). We conclude that the only protein-coding transcript from LEMD2 in spermatids encodes a short version of LEMD2 that we have termed LEMD2_A115-259 since it lacks amino acids 115-259 of the full-length protein. The cryptic splice site in exon 1 that allows the production of the alternative transcripts is not present in mouse and we were unable to detect corresponding transcripts in the mouse (data not shown). We amplified using PCR and cloned the coding region of the LEMD2 $\triangle 115-259$ transcript as a single amplicon from testis cDNA, sequenced it and deposited it in Genbank (accession KY056761).

\section{LEMD2_ $\triangle 115-259$ is not directed to nuclear periphery and does not destabilise $N E$}

It has been concluded that LEMD2 is important for nuclear integrity, as its depletion from somatic cells leads to altered nuclear morphology (Ulbert et al. 2006), similar to that induced by ectopic expression of the spermatidspecific lamin B3 (Schütz et al. 2005, Elkhatib et al. 2015). We therefore investigated the possibility that LEMD2_ $\Delta 115-259$ has a role in destabilising the NE to facilitate nuclear remodelling in spermatids. To do this we expressed both isoforms with a C-terminal Flag tag in HeLa cells. We observed that while the fulllength isoform was directed to the nuclear periphery as expected, LEMD2_A115-259 was not, and was visible in 

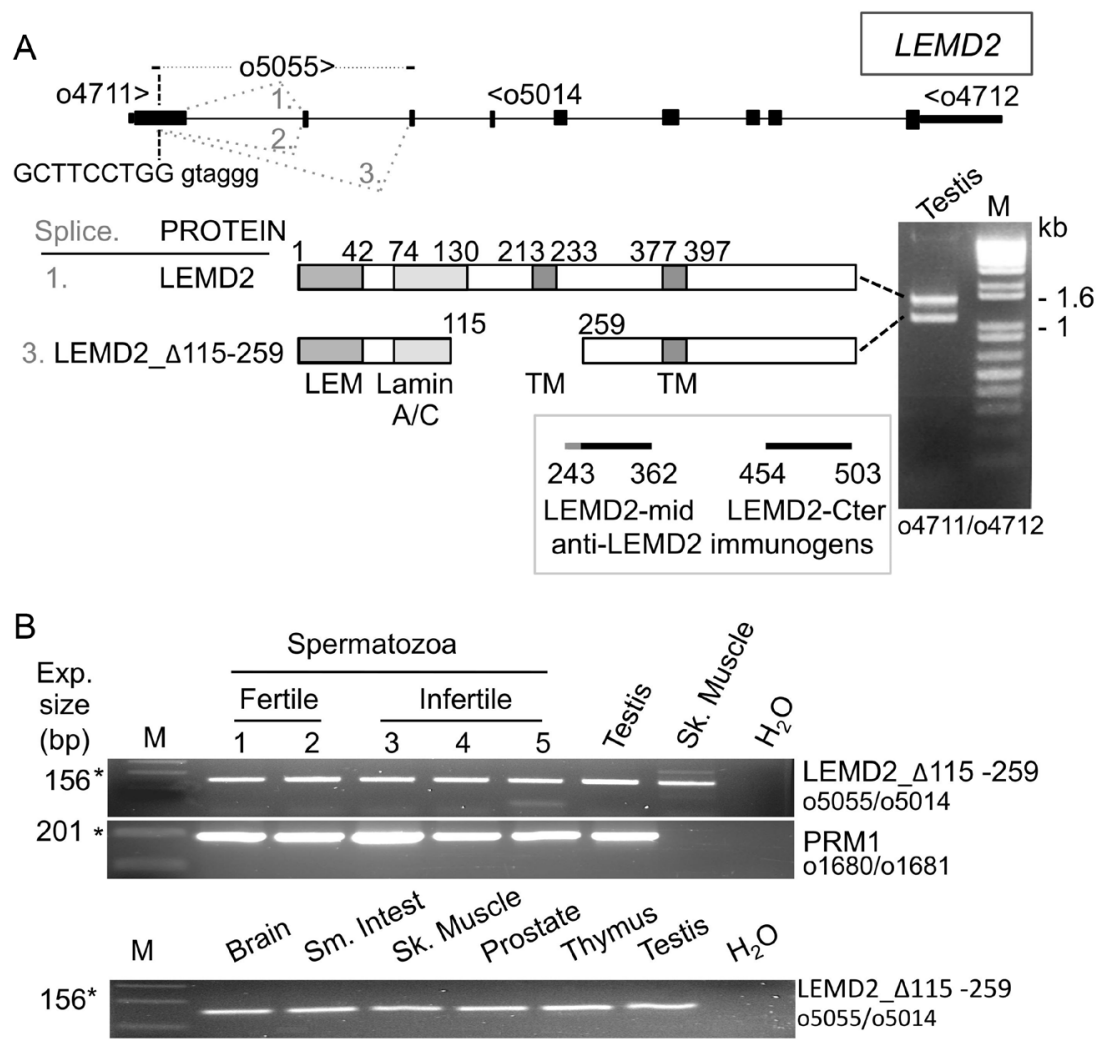

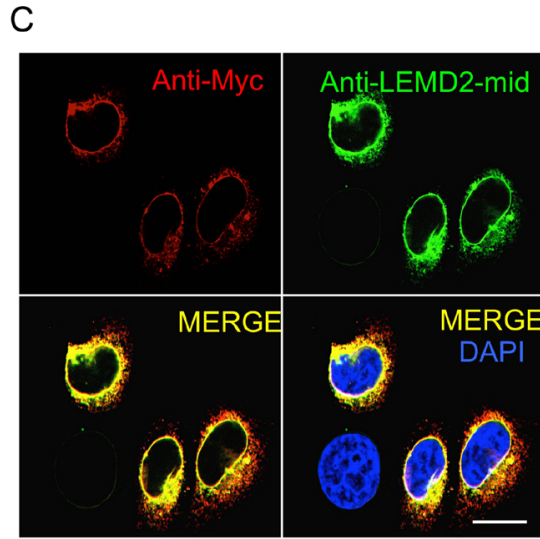

Transfected: Myc-LEMD2

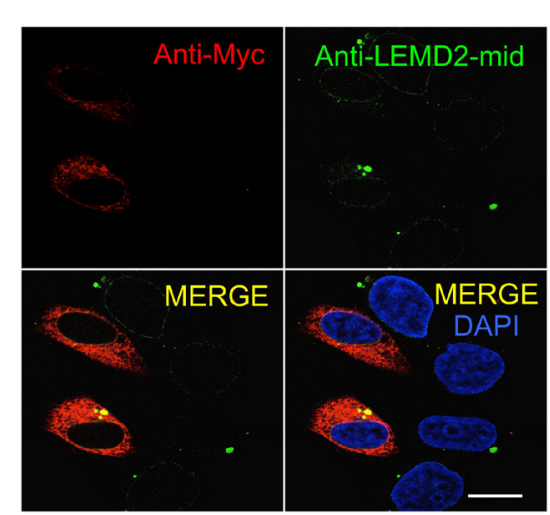

Transfected: Myc-LEMD2_A115-259
Figure 5 An alternative transcript for LEMD2 is present in spermatids. (A) Schematic representation of LEMD2 full-length isoform with the position of primers used in RT-PCR analyses and the cryptic splice site that leads to the alternative transcript encoding LEMD2_A115-259. Primer o5055 is specific for the LEMD2_ $\Delta 115-259$ transcript. Primers o4711 and o4712 were used to amplify the full coding region from testis RNA and generated two bands (right panel) that were sequenced and the predicted proteins encoded by these transcripts are represented schematically with the different domains (TM: transmembrane) mapped to LEMD2 (Brachner et al. 2005). (B) RT-PCR analysis of the alternative transcript encoding LEMD2_ $\Delta 115-259$ in human spermatozoa (individuals 1-5 in Table 1), and six tissues: brain, small intestine, skeletal muscle, prostate, thymus and testis. PCR products were migrated on $3 \%$ agarose gels. The ladder is $1 \mathrm{~kb}$ plus (Life Technologies), and the $200 \mathrm{bp}$ band is indicated with an $(*)$. (C) Ectopic expression of fusion proteins LEMD2 and LEMD2_A115259 (green) with C-terminal Flag tag (red) in HeLa cells. Only LEMD2 transfected cells were labelled with anti-LEMD2 (Sigma HPA017340), indicating that this antibody is specific for the full-length isoform of LEMD2. Scale bar is $10 \mu \mathrm{m}$. the perinuclear region of the cytoplasm. LEMD2_ $\triangle 115-$ 259 did not induce any nuclear deformation (Fig. 5C). Taken together with previous work (Brachner et al. 2005) showing that LEMD2 lacking amino acids 130-203 is directed to the nuclear periphery, our results show that at least part of a domain necessary for the import of LEMD2 from the cytoplasm to the nuclear periphery, must be located within amino acids (aas) 115-130 and aas 203-259. In addition, our IF analysis of transfected cells shows that the anti-LEMD2 antibody HPA017340, whose immunogen (aa 243-362) overlaps with aas 115259 of LEMD2 is essentially specific for the full-length LEMD2 isoform, and does not detect LEMD2_A115-259 (Fig. 5C). The epitopes detected with high affinity by
HPA017340 must therefore all overlap with aa 243-259 of LEMD2.

\section{Nuclear LEM-domain proteins and LBR not at nuclear periphery in human spermatids}

In order to explore the nature of the interface between the $\mathrm{NL}$ and the chromatin during human spermiogenesis, we performed IF analysis of testicular germ cells from four men with antibodies against six LEM-domain proteins, the two BAF proteins and LBR (antibody descriptions Supplementary Table 2). We detected signals on spermatids for LEMD1, LEMD2, ANKLE2, LAP2 $\beta$, BAF and BAF-L (Fig. 6, Table 2 and Supplementary Fig. 3), but 


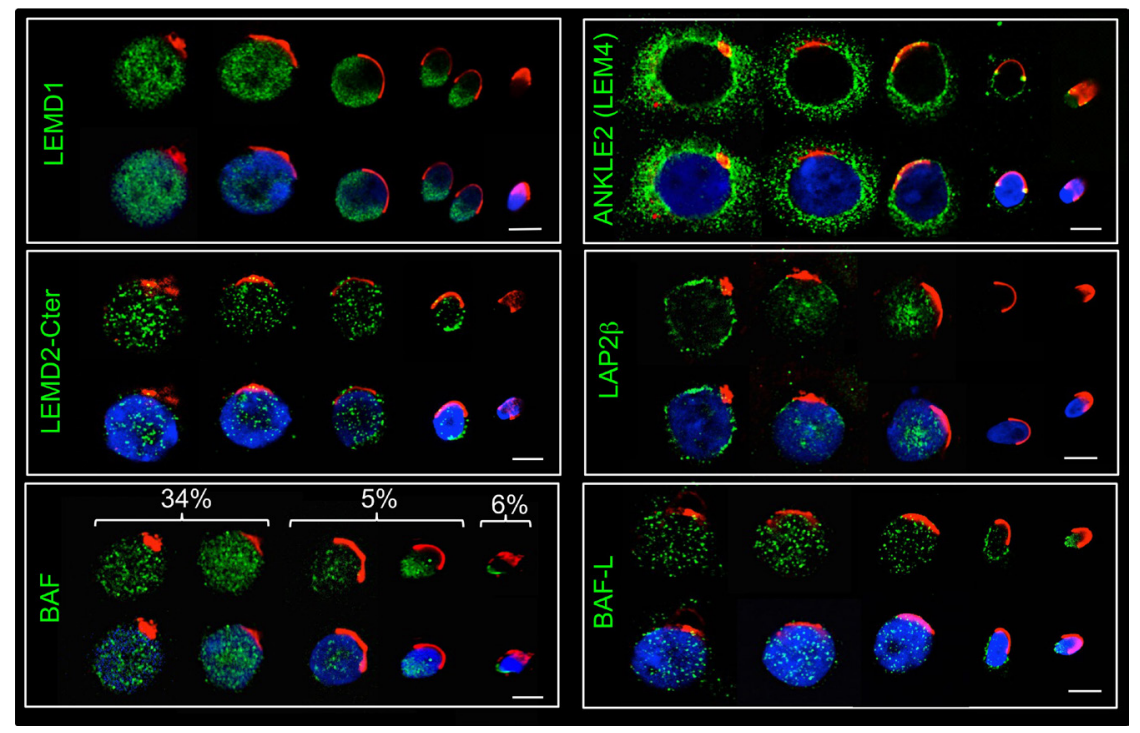

Figure 6 Immunolocalisation of LEM-domain proteins and BAF proteins (green) on human spermatids and testicular spermatozoa. Labelling is shown on successive steps of spermatid development: early, mid and late round, early elongating and testicular spermatozoa. The antibodies used are indicated in green. Spermatids are identified using lectin PNA (red) and DNA counterstained with DAPI (blue). Exposures have been normalised on Sertoli cell labelling. Scale bar is $10 \mu \mathrm{m}$.

no signal was observed on spermatids with antibodies against Emerin, LBR or LEMD3, despite strong labelling of the nuclear periphery in somatic cells on the same slide (Supplementary Figs 4 and 5).

For Emerin, we had amplified a transcript from spermatozoa RNA by RT-PCR, and it was therefore unexpected that Emerin was not detected in spermatids. We therefore tested two different anti-Emerin antibodies that labelled the nuclear periphery in somatic cells (Supplementary Fig. 6). Neither labelled any spermatids nor any spermatozoa (Leica-Emerin-Ncl and AMAb90560) (Supplementary Fig. 6). Moreover, in Human Protein Atlas, further two antibodies, HPA000609 and CAB001545, do not label spermatids.
Thus, although we have shown that the Emerin transcript is present in spermatids, we conclude that it is not translated and that the Emerin protein is not present in spermatids or spermatozoa.

Using antibodies directed against LEMD1 we observed a nucleoplasmic signal in round spermatids, except in the area covered by the acrosome. As spermatid maturation progressed, the fluorescence became limited progressively to the posterior pole of the nuclei, where it remained visible in late elongated spermatids. LEMD1 was not detected, however, on testicular spermatozoa or on ejaculated spermatozoa (Fig. 6).

For LEMD2, our RT-PCR analyses suggested that in spermatids LEMD2 was only present as an isoform lacking

Table 2 The presence (+) or absence (-) of LEM-domain proteins, BAF proteins, LBR and lamins, and their respective transcripts in human spermatids and spermatozoa, as determined by us in this study or previously (Elkhatib et al. 2015).

\begin{tabular}{|c|c|c|c|}
\hline & \multirow{2}{*}{$\begin{array}{c}\text { Transcript (RT-PCR) } \\
\text { Ejac. sperm. }\end{array}$} & \multicolumn{2}{|c|}{ Protein (IF) } \\
\hline & & Spermatid & Ejac. sperm. \\
\hline LEMD1 & + & + & - \\
\hline LEMD2-full & - & - & - \\
\hline LEMD2- $\triangle 115-259$ & + & + & - \\
\hline LEMD3 & - & - & - \\
\hline ANKLE2 & + & + & - \\
\hline ANKLE2_ $\Delta 1-64$ & + & nd & - \\
\hline ANKLE1 & - & nd & nd \\
\hline LAP $2 \alpha$ & + & nd & nd \\
\hline LAP2 $\beta$ & + & + & - \\
\hline Emerin & + & - & - \\
\hline LBR & - & - & - \\
\hline BAF & - & + & + \\
\hline BAF-L & + & + & + \\
\hline Lamin A & - & - & - \\
\hline Lamin C & - & - & - \\
\hline Lamin B1 & + & + & + \\
\hline Lamin B2 & - & $+?$ & - \\
\hline Lamin B3 & + & $+?$ & nd \\
\hline
\end{tabular}

nd, not determined; + ?, the absence of an antibody that discriminates between lamin B2 and lamin B3 prevents us from determining which is present. 
aas 115-259. We therefore analysed testicular germ cells with two antibodies, anti-LEMD2_243-362 (Sigma HPA017340) that detects the full-length LEMD2 isoform but not LEMD2_A115-259 (Fig. 5C and Supplementary Fig. 3), and anti-LEMD2_Cter that detects both isoforms (Supplementary Fig. 2). Despite strong labelling of the nuclear periphery in somatic cells of disaggregated testis with both antibodies, only anti-LEMD2_Cter labelled the nuclei of spermatids, confirming that in spermatids, LEMD2 is present only as the short isoform LEMD2_A115-259 (Fig. 6 and Supplementary Fig. 3). Anti-LEMD2_Cter gave a punctate labelling throughout the spermatid nucleoplasm, indicating that LEMD2 $\Delta 115-259$ does not localise to the nuclear periphery in spermatids (Fig. 5C).

For LAP2 $\beta$, labelling is nuclear, and predominates at the nuclear periphery in the earliest round, spermatids but the signal shifts to the nucleoplasm at later steps and is not detected in elongating spermatids (Fig. 6). In the rat, the nucleoplasm and NE labelling in round spermatids were previously demonstrated with an antibody that detected all LAP2 isoforms (Alsheimer et al. 1998).

The anti-BAF-L antibody gave a granular signal concentrated over the nucleoplasm of round spermatids, with fainter fluorescence in the cytoplasm. Labelling was concentrated at the nuclear periphery in elongating spermatids, but was excluded from under the acrosome (Fig. 6). In testicular and ejaculated spermatozoa BAF-L labelling was visible at the posterior pole of the nucleus (Fig. 7A).
Although no BAF transcript was detected in spermatozoa RNA from four of five men tested, the anti-BAF antibody (ab129184) labelled the nuclei of spermatids (Fig. 6). We observed a nucleoplasmic localisation of BAF in $10-55 \%$ of round spermatids, $2-9 \%$ of elongated spermatids, and $1-10 \%$ of testicular spermatozoa, where BAF was located at the posterior pole of the nucleus (Fig. 6 and Supplementary Figs 5B and $7 \mathrm{~A})$. BAF signal was observed in ejaculated spermatozoa at the posterior nuclear pole in all 3 patients tested with a mean of $30 \%$ of spermatozoa labelled (Fig. 7A). These contradictory results for the expression of the BAF protein and its transcript imply either that the BAF spermatid transcript is a remnant from spermatocytes (BAF protein labelling is seen throughout the spermatocyte nucleus - Supplementary Fig. 7C), or that de novo BAF transcripts are produced in spermatids but are not retained in spermatozoa.

\section{$B A F$ and BAF-L are present in human ejaculated spermatozoa}

Our IF analyses of human spermatids indicate that most of the proteins tested as potential links between the NL and the chromatin are lost during the round spermatid steps and do not persist in spermatozoa. The only exceptions were with the antibodies against BAF and BAF-L that labelled the posterior nuclear pole of testicular and ejaculated spermatozoa. These signals were absent when we pre-absorbed the antibodies with
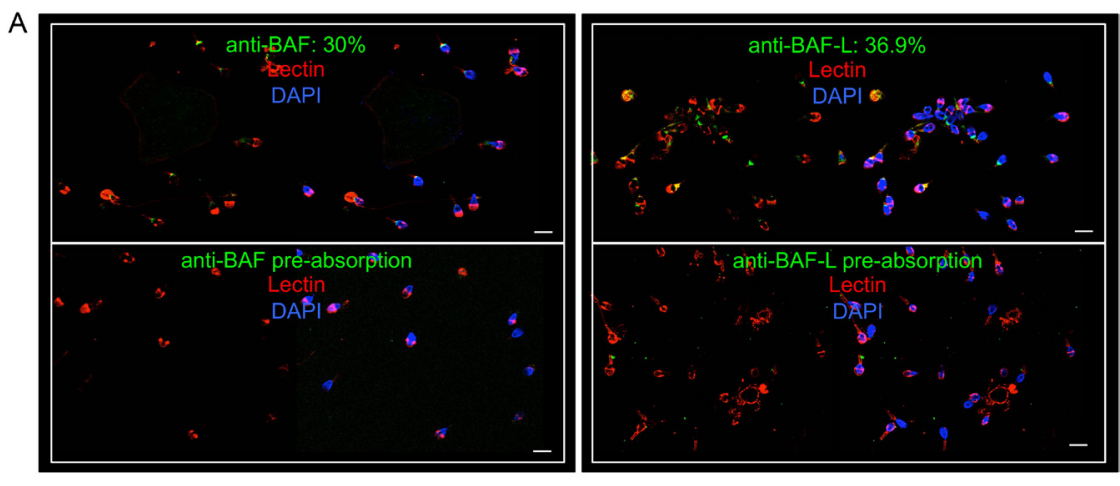

B

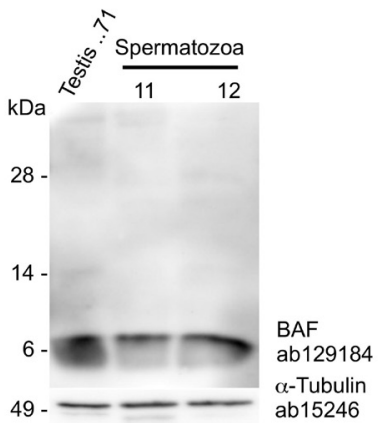

Figure 7 Immunolocalisation of BAF and BAF-L on human ejaculated spermatozoa. (A) Composite montage of spermatozoa labelled with BAF and BAF-L (green). BAF and BAF-L were detected respectively in $30 \%$ and $36.9 \%$ of mature ejaculated spermatozoa, at the posterior pole of the nucleus (upper panels). No labelled spermatozoa were observed when each antibody was pre-absorbed with its immunogen peptide (lower panels). Acrosomes were labelled using lectin PNA (red) and the nucleus is stained with DAPI (blue). Scale bar is $10 \mu \mathrm{m}$. (B) Protein expression of BAF and BAF-L by western blot analysis of human spermatozoa lysates. Results are shown for human testis (T011400051, T011500055, T011400062 and T011400071) (20 $\mu \mathrm{g})$ and three spermatozova samples $\left(2 \times 10^{6}\right.$ spermatozoa) corresponding to individuals $11-13$ in Table 1 . The anti- $\alpha$ tubulin antibody was used, on the same membranes without prior stripping, as a loading control. In order to reveal the faint signal of BAF-L in whole testis lysates, a long exposure of a segment of the BAF-L blot (between the grey bars) was compressed vertically and is shown below the $\alpha$-tubulin result. 
their respective immunising peptide, indicating that they were specific for BAF and BAF-L (Fig. 7A). To further verify that this signal was due to the presence of BAF and BAF-L, we performed western blot analysis of lysates of purified spermatozoa with the same antibodies (Fig. 7B). The anti-BAF and anti-BAF-L antibodies detected a strong band of the expected size, approximately $10 \mathrm{kDa}$, in protein lysates from spermatozoa. Anti-BAF detected a strong band of the same size in testis lysates, but in the case of BAF-L the band was barely detectable in whole testis, suggesting that it is expressed in spermatids at a low level and becomes concentrated in the spermatozoa fraction (Fig. 7B). We conclude that BAF and BAF-L proteins are present in spermatids throughout human spermiogenesis and are retained in ejaculated spermatozoa.

\section{Discussion}

\section{Known somatic lamina-chromatin interface absent from all but earliest spermatids}

Here, we present an overview of how LEM-domain proteins, BAF proteins and LBR, many known to be involved in linking the NL to the chromatin in somatic cells, are organised in human spermatids and spermatozoa. For most of the proteins, except LBR and LAP $2 \beta$, this is the first study of these proteins during mammalian spermiogenesis. We have studied ANKLE1 and LAP $2 \alpha$ expression only at the transcript level.

Based on our observations, a general theme emerges that during most of spermiogenesis the laminachromatin interface, as defined in somatic cells, does not exist, and the three LEM-domain proteins that we did detect, LEMD1, LEMD2_A115-259 and LAP2 $\beta$, do not localise to the NE in most round spermatids, but to the nucleoplasm. This can readily be explained for LEMD2_ $\triangle 115-259$ based on our HeLa transfection experiments showing that LEMD2_A115-259 lacks the domains required for NE localisation, consistent with the mapping of these domains to aas 74-130 and aas 203378 (Brachner et al. 2005). It is more difficult to explain the nucleoplasmic localisation of LEMD1 and LAP2 $\beta$. Both contain a transmembrane domain (TM), which has been shown to be necessary for the efficient localisation of LAP2 $\beta$ to the NE (Furukawa et al. 1995). LAP2 $\beta$ is found at the INM in somatic cells (Foisner \& Gerace 1993) (Supplementary Fig. 3) and tagged-LEMD1 transfected into HeLa cells localises, as does Emerin (Tsuchiya et al. 1999), to a perinuclear cytoplasmic structure and the NE (Supplementary Fig. 2). Indeed, LAP2 $\beta$ is peripheral in the earliest round spermatids, but becomes exclusively nucleoplasmic at all later steps (Fig. 6). We suggest that proteins required for the direction of LEMD1 and LAP2 $\beta$ to the NE in somatic cells are unavailable in spermatids or that spermatid-specific proteins direct them to the nucleoplasm.
LAP2 $\beta$ is known to localise to the NE in part by interacting with lamin B1 (Furukawa et al. 1998), which is present at the INM in human spermatids (Elkhatib et al. 2015). It is therefore possible that changes in the NL block the access of LAP2 $\beta$ to lamin B1. It is unlikely that loss of LAP2 $\beta$ from the NE in spermatids is a direct consequence of lamin B3 recruitment or LEMD2 absence because it has been shown that the overexpression of lamin B3 or knockdown of LEMD2 in HeLa cells does not affect the localisation of LAP2 $\beta$ to the NE (Schütz et al. 2005, Ulbert et al. 2006). Nevertheless, the displacement of LAP2 $\beta$ from the nuclear periphery could have a functional significance during spermiogenesis, since BAF-L and LEMD1, which are predominantly expressed in human and mouse spermatids (Fig. 2), are also nucleoplasmic in round spermatids (Fig. 6 and Supplementary Fig. 3).

The absence of the known somatic lamina-chromatin interface from most spermatids is probably related to the unique extreme chromatin remodelling that occurs during spermiogenesis. It is interesting that the somatic lamina-chromatin interface is no longer required in round spermatids even though there is still a high transcriptional activity to produce the proteins that will allow the round spermatid to become a spermatozoon. Indeed the priority in spermatids may be to detach the chromatin from the lamina to increase accessibility for histone-protamine exchange, since the lamina itself gradually disappears from the nuclear periphery in synchrony with the spread of protamine-packed chromatin (Alsheimer et al. 2004, De Vries et al. 2012, Elkhatib et al. 2015). We do not know whether a specific structure continues to link the histone-packed chromatin to the lamina in spermatids, or whether the lamina becomes completely detached from the chromatin early during spermiogenesis. One way of exploring the former possibility would be to try to identify partners of lamin B1 or lamin B3 in purified round spermatids.

\section{$L B R$ is not detected in human spermatids}

We did not detect the expression of LBR in spermatids at either the RNA or the protein level. In the mouse, LBR has been localised to the nuclear periphery in elongating spermatids, and based on an interaction in transfected cells with protamine 1 , it has been suggested that LBR plays a role in the replacement of histones by protamines during spermiogenesis (Mylonis et al. 2004). Our finding is supported by results with antiLBR antibody HPA049840 (Human Protein Atlas) that labels the nuclear periphery of only the spermatogonia in the seminiferous tubule. This discrepancy with the mouse may indicate that LBR is expressed differently between rodents and human, or it might arise from a lack of antibody specificity in the mouse study, where the antibody against mouse LBR was raised against the $\mathrm{N}$-terminal amino acids 1-201 that includes a conserved 
highly immunogenic stretch $\left({ }^{78}\right.$ SRSRSRSRSRSRSP $\left.{ }^{91}\right)$ that contains peptides found in more than a hundred different mouse proteins. In contrast, the LBR epitopes detected by the antibody ab32535 (aa 1-60) that we used here, and HPA049840 (aa 1-71) that is presented in Human Protein Atlas do not overlap with ${ }^{78}$ SRSRSRSRSRSRSP ${ }^{91}$. Whatever the explanation for this discrepancy, our data together with those in Human Protein Atlas provide strong evidence that LBR is not present in human spermatids, and is therefore not involved in the deposition of protamine 1 onto the chromatin during human spermiogenesis.

\section{Increasing flexibility of the spermatid $N L$}

In mouse and human, the lamin B2 isoform, lamin B3, is recruited to the NE during spermiogenesis and has been demonstrated to deform the NE when expressed in cultured cells (Schütz et al. 2005, Elkhatib et al. 2015). This has been interpreted to indicate that the flexibility of the spermatid NE is increased to facilitate the remodelling of the nucleus into an elongated form. We have shown, however, that neither LEMD2 $\Delta 115-259$ nor ANKLE2_ $\Delta 1-64$ share the ability of lamin B3 to deform the NE when transfected into HeLa cells. We have also found that orthologous

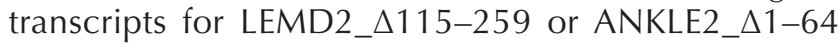
are not expressed in the mouse (data not shown). We conclude that the ANKLE2_ $\triangle 1-64$ and LEMD2 $\Delta 115-259$ transcripts are either biological artefacts or primate-specific measures to regulate ANKLE2 and LEMD2 expression. It has however been shown that the reduction of LEMD2 level in HeLa cells (Ulbert et al. 2006) causes the same type of nuclear deformations as the ectopic expression of lamin B3. Thus, the absence of the full-length LEMD2 isoform from the spermatid nucleus, with lamin B3 expression, could be part of the same strategy to produce a flexible NE. We conclude that it is more likely the absence of the full-length conserved LEMD2 isoform, and not the presence of the LEMD2_A115-259 isoform, that has functional significance for the shaping of the spermatozoon nucleus.

\section{$B A F$ and BAF-L may regulate condensation of the paternal chromatin}

Our finding that both BAF and BAF-L are present in spermatozoa is an exciting one. Indeed, on western blot analysis, the signal obtained for each protein is at least as strong in spermatozoa as in whole testis, implying that both are abundant in spermatozoa. This is very obvious for BAF-L where we detected a very weak signal in whole testis (Fig. 7B). This implies that the retention of BAF and BAF-L in spermatozoa may be functionally important. BAF and BAF-L both form homodimers, but are able to form heterodimers in vitro and on co-transfection into cultured cell lines (Tifft et al. 2006). BAF can bind DNA and LAP2 $\beta$ simultaneously, but BAF-L cannot bind DNA or LAP2 $\beta$ on its own (Tifft et al. 2006). Nevertheless, BAF-BAF-L heterodimers are able to bind DNA and LAP2 $\beta$ (Tifft et al. 2006). Furthermore, we have shown that ANKLE2, necessary for the recruitment of BAF to the chromatin at mitotic exit (Asencio et al. 2012), is present on the ER in round spermatids. It is therefore of critical significance that both BAF and BAF-L proteins are present in spermatids and spermatozoa, since it opens up the possibility that, through its interaction with BAF, BAF-L could be a component of the sperm chromatin.

The specific role of BAF-L during spermiogenesis is unclear, but the formation of BAF-BAF-L heterodimers might serve to prevent BAF homodimer formation on the nucleohistone chromatin of round spermatids. BAF homodimers are able to cross-link two double stranded (ds) DNA molecules, form dodecamer complexes with dsDNA, and induce condensation of the chromatin (Zheng et al. 2000, Skoko et al. 2009). In contrast, BAF-BAF-L heterodimers can only bind to a single DNA molecule and so could promote a more open chromatin that facilitates the massive histoneprotamine exchanges that occur during spermiogenesis and during the formation of the male pronucleus in the oocyte cytoplasm. In support of this hypothesis, the concentration of BAF has been shown to be critical for correct chromatin decondensation of sperm chromatin in Xenopus egg extracts, with as little as a $20 \%$ increase in BAF concentration inducing excessive chromatin condensation and preventing NE assembly (SeguraTotten et al. 2002).

\section{BAF-L may regulate timing of NE formation on paternal chromatin in oocytes}

In mouse and Xenopus oocytes, the formation of a sealed nuclear membrane can occur around the paternal chromatin artificially depleted for nucleosomes, but in the absence of nucleosomes, NPCs are not recruited, preventing nuclear import notably of NL components, and a failure of nuclear expansion and zygotic development (Inoue \& Zhang 2014, Zierhut et al. 2014). A mechanism must therefore exist that ensures delay of nuclear membrane assembly on the paternal chromatin until the histones have been integrated. In somatic cells, BAF recruitment to the surface of the chromosomes at mitotic exit is an early and essential step in the reassembly of the NE (Haraguchi et al. 2008). Furthermore, BAF can behave like a DNA-sensor and binds rapidly to histone-free dsDNA transferred into the cytoplasm of cultured cells, promoting assembly of NE-like membranes (Kobayashi et al. 2015). Thus, another possible role for BAF-L in the oocyte could be to delay the onset of BAF-dependent assembly of the NE until after nucleosome incorporation. 


\section{Conclusion and perspectives}

Our study reveals that except for LAP2 $\beta$ in the earliest round spermatids, none of the components of the NL-chromatin interface defined in somatic cells is present at the nuclear periphery of germ cells during human spermiogenesis, and the definition of the NL-chromatin interface in spermatids, if it exists, now requires the identification of proteins that interact with lamin B1 and lamin B3 in spermatids.

An important finding of our study is that BAF and BAF-L are present in ejaculated human spermatozoa, where they could be chromatin components with roles in the formation of the spermatozoon nucleus and its transformation into the male pronucleus. Our study therefore opens new perspectives for the study of paternal chromatin remodelling, during spermiogenesis and immediately after fertilisation, which we will now explore through the study of mice inactivated for BAF$\mathrm{L}$. We predict that, given BAF's central role in mitosis, and the severe somatic phenotype associated with loss of BAF function (Puente et al. 2011), it will be extremely unlikely to find BAF mutations causal of isolated male infertility in human. Mutations in BAF-L however, with its spermatid-predominant expression, could cause isolated male infertility and might be found by targeting infertile men whose spermatozoa retain high levels of histones or fail to achieve a functional pronucleus following in vitro fertilisation. We will use the mouse model to better predict the spermatogenic phenotype that might be associated with loss of BAF-L function in men. Studying the roles of BAF and BAF-L in the context of male fertility should provide fresh insights into the relationship between chromatin remodelling and the quality of the sperm nucleus.

\section{Supplementary data}

This is linked to the online version of the paper at http://dx.doi. org/10.1530/REP-17-0358.

\section{Declaration of interest}

The authors declare that there is no conflict of interest that could be perceived as prejudicing the impartiality of the research reported.

\section{Funding}

This work was supported by grants from the Agence de la biomédecine, AOR 'AMP, diagnostic prenatal et diagnostic génétique' 2013 (Lamina nucléaire et spermiogenèse), Inserm and Aix-Marseille Université. The Germetheque biobank was supported by grants from the ANR (Agence Nationale de la Recherche), the Agence de la biomedicine, the Centre Hospitalier Universitaire of Toulouse and APHM (Assistance
Publique Hôpitaux de Marseille). R A E was funded by the Islamic Development Bank and the Lebanese Association for Scientific Research (LASeR).

\section{Author's contribution statement}

$\mathrm{R}$ A E performed most of the experimental work, and was involved in the manuscript writing. $\mathrm{MP}$ and $\mathrm{Y} A$ were involved in immunofluorescence techniques. C M G, R B, P B, V A and $\mathrm{N} B$ played a role in the patient recruitment. $G L$ organised and supervised cell transfection and RT-PCR experiments. M J M performed western blot experiments. C M G and M J $M$ were particularly involved in the study conception and the manuscript writing with $\mathrm{RAE}$ and $\mathrm{N} \mathrm{L}$. C M G and M J M took direct responsibility for the manuscript.

\section{Acknowledgements}

The authors are grateful to the patients who gave their informed consent to use their samples for research. The authors also thank doctor J C Colavolpe and the 'Coordination Hospitalière de Prélèvement d'Organes et de Tissus' team for their help collecting human testis samples, C Metton and M J Fays-Bernardin for technical assistance and Germetheque support. M J Mitchell and C Metzler-Guillemain are equal senior authors.

\section{References}

Alsheimer M, Fecher E \& Benavente R 1998 Nuclear envelope remodelling during rat spermiogenesis: distribution and expression pattern of LAP2/ thymopoietins. Journal of Cell Science 111 2227-2234.

Alsheimer M, Liebe B, Sewell L, Stewart CL, Scherthan H \& Benavente R 2004 Disruption of spermatogenesis in mice lacking A-type lamins. Journal of Cell Science 117 1173-1178. (doi:10.1242/jcs.00975)

Asencio C, Davidson IF, Santarella-Mellwig R, Ly-Hartig TBN, Mall M, Wallenfang MR, Mattaj IW \& Gorjánácz M 2012 Coordination of kinase and phosphatase activities by Lem4 enables nuclear envelope reassembly during mitosis. Cell 150 122-135. (doi:10.1016/j.cell.2012.04.043)

Auger J, Jouannet P \& Eustache F 2016 Another look at human sperm morphology. Human Reproduction 31 10-23. (doi:10.1093/humrep/ dev251)

Brachner A, Reipert S, Foisner R \& Gotzmann J 2005 LEM2 is a novel MAN1-related inner nuclear membrane protein associated with A-type lamins. Journal of Cell Science 118 5797-5810. (doi:10.1242/jcs.02701)

Brachner A, Braun J, Ghodgaonkar M, Castor D, Zlopasa L, Ehrlich V, Jiricny J, Gotzmann J, Knasmuller S \& Foisner R 2012 The endonuclease Ankle1 requires its LEM and GIY-YIG motifs for DNA cleavage in vivo. Journal of Cell Science 125 1048-1057. (doi:10.1242/jcs.098392)

Burke B \& Stewart CL 2013 The nuclear lamins: flexibility in function. Nature Reviews: Molecular Cell Biology 14 13-24. (doi:10.1038/ nrm3488)

Cai M, Huang Y, Ghirlando R, Wilson KL, Craigie R \& Clore GM 2001 Solution structure of the constant region of nuclear envelope protein LAP2 reveals two LEM-domain structures: one binds BAF and the other binds DNA. EMBO Journal 20 4399-4407. (doi:10.1093/emboj/20.16.4399)

Calvi A, Wong ASW, Wright G, Wong ESM, Loo TH, Stewart CL \& Burke B 2015 SUN4 is essential for nuclear remodeling during mammalian spermiogenesis. Developmental Biology 407 321-330. (doi:10.1016/j.ydbio.2015.09.010)

De Vries M, Ramos L, Housein Z \& De Boer P 2012 Chromatin remodelling initiation during human spermiogenesis. Biology Open 1 446-457. (doi:10.1242/bio.2012844)

Elkhatib R, Longepied G, Paci M, Achard V, Grillo J-M, Levy N, Mitchell MJ \& Metzler-Guillemain C 2015 Nuclear envelope 
remodelling during human spermiogenesis involves somatic B-type lamins and a spermatid-specific B3 lamin isoform. Molecular Human Reproduction 21 225-236. (doi:10.1093/molehr/gau111)

Elkhatib RA, Paci M, Longepied G, Saias-Magnan J, Courbiere B, Guichaoua MR, Levy N, Metzler-Guillemain C \& Mitchell MJ 2017 Homozygous deletion of SUN5 in three men with decapitated spermatozoa. Human Molecular Genetics (Epub ahead of print). (doi:10.1093/hmg/ddx200)

Foisner R \& Gerace L 1993 Integral membrane proteins of the nuclear envelope interact with lamins and chromosomes, and binding is modulated by mitotic phosphorylation. Cell 73 1267-1279. (doi:10.1016/0092-8674(93)90355-T)

Furukawa K 1999 LAP2 binding protein 1 (L2BP1/BAF) is a candidate mediator of LAP2-chromatin interaction. Journal of Cell Science 112 2485-2492.

Furukawa K, Panté N, Aebi U \& Gerace L 1995 Cloning of a cDNA for lamina-associated polypeptide 2 (LAP2) and identification of regions that specify targeting to the nuclear envelope. EMBO Journal 14 1626-1636.

Furukawa K, Fritze CE \& Gerace L 1998 The major nuclear envelope targeting domain of LAP2 coincides with its lamin binding region but is distinct from its chromatin interaction domain. Journal of Biological Chemistry 273 4213-4219. (doi:10.1074/jbc.273.7.4213)

Göb E, Schmitt J, Benavente R \& Alsheimer M 2010 Mammalian sperm head formation involves different polarization of two novel LINC complexes. PLoS ONE 5 e12072. (doi:10.1371/journal.pone.0012072)

Goldman RD, Gruenbaum Y, Moir RD, Shumaker DK \& Spann TP 2002 Nuclear lamins: building blocks of nuclear architecture. Genes and Development 16 533-547. (doi.10.1101/gad.960502)

Gruenbaum Y, Margalit A, Goldman RD, Shumaker DK \& Wilson KL 2005 The nuclear lamina comes of age. Nature Reviews: Molecular Cell Biology 6 21-31. (doi:10.1038/nrm1550)

Haraguchi T, Kojidani T, Koujin T, Shimi T, Osakada H, Mori C, Yamamoto A \& Hiraoka Y 2008 Live cell imaging and electron microscopy reveal dynamic processes of BAF-directed nuclear envelope assembly. Journal of Cell Science $\mathbf{1 2 1}$ 2540-2554. (doi:10.1242/ jcs.033597)

Harbuz R, Zouari R, Pierre V, Ben Khelifa M, Kharouf M, Coutton C, Merdassi G, Abada F, Escoffier J, Nikas Y et al. 2011 A recurrent deletion of DPY19L2 causes infertility in man by blocking sperm head elongation and acrosome formation. American Journal of Human Genetics 88 351-361. (doi:10.1016/j.ajhg.2011.02.007)

Inoue A \& Zhang Y 2014 Nucleosome assembly is required for nuclear pore complex assembly in mouse zygotes. Nature Structural and Molecular Biology 21 609-616. (doi:10.1038/nsmb.2839)

Kierszenbaum AL \& Tres LL 2004 The acrosome-acroplaxome-manchette complex and the shaping of the spermatid head. Archives of Histology and Cytology 67 271-284. (doi:10.1679/aohc.67.271)

Kobayashi S, Koujin T, Kojidani T, Osakada H, Mori C, Hiraoka Y \& Haraguchi T $2015 \mathrm{BAF}$ is a cytosolic DNA sensor that leads to exogenous DNA avoiding autophagy. PNAS 112 7027-7032. (doi:10.1073/ pnas.1501235112)

Koscinski I, Elinati E, Fossard C, Redin C, Muller J, de la Calle Velez J, Schmitt F, Ben Khelifa M, Ray PF, Kilani Z et al. 2011 DPY19L2 deletion as a major cause of globozoospermia. American Journal of Human Genetics 88 344-350. (doi:10.1016/j.ajhg.2011.01.018)

Lambard S, Galeraud-Denis I, Saunders PTK \& Carreau S 2004 Human immature germ cells and ejaculated spermatozoa contain aromatase and oestrogen receptors. Journal of Molecular Endocrinology 32 279-289. (doi:10.1677/jme.0.0320279)

Lee MS \& Craigie R 1998 A previously unidentified host protein protects retroviral DNA from autointegration. PNAS 95 1528-1533. (doi:10.1073/ pnas.95.4.1528)

Lee KK \& Wilson KL 2004 All in the family: evidence for four new LEM-domain proteins Lem2 (NET-25), Lem3, Lem4 and Lem5 in the human genome. Symposia of the Society for Experimental Biology $\mathbf{5 6}$ 329-339.

Lee KK, Haraguchi T, Lee RS, Koujin T, Hiraoka Y \& Wilson KL 2001 Distinct functional domains in emerin bind lamin A and DNA-bridging protein BAF. Journal of Cell Science 114 4567-4573.

Mansharamani M \& Wilson KL 2005 Direct binding of nuclear membrane protein MAN1 to emerin in vitro and two modes of binding to barrier-to-autointegration factor. Journal of Biological Chemistry 280 13863-13870. (doi:10.1074/jbc.M413020200)

Margalit A, Brachner A, Gotzmann J, Foisner R \& Gruenbaum Y 2007 Barrier-to-autointegration factor - a BAFfling little protein. Trends in Cell Biology 17 202-208. (doi:10.1016/j.tcb.2007.02.004)

Metzler-Guillemain C \& Guichaoua MR 2000 A simple and reliable method for meiotic studies on testicular samples used for intracytoplasmic sperm injection. Fertility and Sterility 74 916-919. (doi:10.1016/S00150282(00)01551-X)

Mylonis I, Drosou V, Brancorsini S, Nikolakaki E, Sassone-Corsi P \& Giannakouros T 2004 Temporal association of protamine 1 with the inner nuclear membrane protein lamin B receptor during spermiogenesis. Journal of Biological Chemistry 279 11626-11631. (doi:10.1074/jbc. M311949200)

Pasch E, Link J, Beck C, Scheuerle S \& Alsheimer M 2015 The LINC complex component Sun4 plays a crucial role in sperm head formation and fertility. Biology Open 4 1792-1802. (doi:10.1242/bio.015768)

Pierre V, Martinez G, Coutton C, Delaroche J, Yassine S, Novella C, PernetGallay K, Hennebicq S, Ray PF \& Arnoult C 2012 Absence of Dpy19l2, a new inner nuclear membrane protein, causes globozoospermia in mice by preventing the anchoring of the acrosome to the nucleus. Development 139 2955-2965. (doi:10.1242/dev.077982)

Puente XS, Quesada V, Osorio FG, Cabanillas R, Cadinanos J, Fraile JM, Ordonez GR, Puente DA, Gutierrez-Fernandez A, Fanjul-Fernandez M et al. 2011 Exome sequencing and functional analysis identifies BANF1 mutation as the cause of a hereditary progeroid syndrome. American Journal of Human Genetics 88 650-656. (doi:10.1016/j. ajhg.2011.04.010)

Schirmer EC \& Foisner R 2007 Proteins that associate with lamins: many faces, many functions. Experimental Cell Research 313 2167-2179. (doi:10.1016/j.yexcr.2007.03.012)

Schütz W, Benavente R \& Alsheimer M 2005 Dynamic properties of germ line-specific lamin B3: the role of the shortened rod domain. European Journal of Cell Biology 84 649-662. (doi:10.1016/j. ejcb.2005.03.001)

Segura-Totten M, Kowalski AK, Craigie R \& Wilson KL 2002 Barrier-toautointegration factor: major roles in chromatin decondensation and nuclear assembly. Journal of Cell Biology 158 475-485. (doi:10.1083/ jcb.200202019)

Shumaker DK, Lee KK, Tanhehco YC, Craigie R \& Wilson KL 2001 LAP2 binds to BAF.DNA complexes: requirement for the LEM domain and modulation by variable regions. EMBO Journal 20 1754-1764. (doi:10.1093/emboj/20.7.1754)

Skoko D, Li M, Huang Y, Mizuuchi M, Cai M, Bradley CM, Pease PJ, Xiao B, Marko JF, Craigie R et al. 2009 Barrier-to-autointegration factor (BAF) condenses DNA by looping. PNAS 106 16610-16615. (doi:10.1073/ pnas.0909077106)

Tifft KE, Segura-Totten M, Lee KK \&Wilson KL 2006 Barrier-to-autointegration factor-like (BAF-L): a proposed regulator of BAF. Experimental Cell Research 312 478-487. (doi:10.1016/j.yexcr.2005.11.013)

Tsuchiya Y, Hase A, Ogawa M, Yorifuji H \& Arahata K 1999 Distinct regions specify the nuclear membrane targeting of emerin, the responsible protein for Emery-Dreifuss muscular dystrophy. European Journal of Biochemistry/FEBS 259 859-865. (doi:10.1046/j.14321327.1999.00112.x)

Ulbert S, Antonin W, Platani M \& Mattaj IW 2006 The inner nuclear membrane protein Lem2 is critical for normal nuclear envelope morphology. FEBS Letters 580 6435-6441. (doi:10.1016/j.febslet.2006.10.060)

World Health Organisation 2009 WHO Laboratory Manual for the Examination of Human Semen and Sperm-Cervical Mucus Interaction. Cambridge: Cambridge University Press.

Worman HJ, Yuan J, Blobel G \& Georgatos SD 1988 A lamin B receptor in the nuclear envelope. PNAS 85 8531-8534. (doi:10.1073/ pnas.85.22.8531)

Yassine S, Escoffier J, Abi Nahed R, Nahed RA, Pierre V, Karaouzene T, Ray PF \& Arnoult C 2015 Dynamics of Sun5 localization during spermatogenesis in wild type and Dpy 1912 knock-out mice indicates that Sun5 is not involved in acrosome attachment to the nuclear envelope. PLOS ONE 10 e0118698. (doi:10.1371/journal.pone.0118698)

Ye Q \& Worman HJ 1994 Primary structure analysis and lamin B and DNA binding of human LBR, an integral protein of the nuclear envelope inner membrane. Journal of Biological Chemistry 269 11306-11311. 
Ye Q, Callebaut I, Pezhman A, Courvalin JC \& Worman HJ 1997 Domain-specific interactions of human HP1-type chromodomain proteins and inner nuclear membrane protein LBR. Journal of Biological Chemistry 272 14983-14989. (doi:10.1074/jbc.272.23.14983)

Yuki D, Lin Y-M, Fujii Y, Nakamura Y \& Furukawa Y 2004 Isolation of LEM domain-containing 1, a novel testis-specific gene expressed in colorectal cancers. Oncology Reports 12 275-280. (doi:10.3892/or.12.2.275)

Zheng R, Ghirlando R, Lee MS, Mizuuchi K, Krause M \& Craigie R 2000 Barrier-to-autointegration factor (BAF) bridges DNA in a discrete, higherorder nucleoprotein complex. PNAS 97 8997-9002. (doi:10.1073/ pnas.150240197)

Zhu F, Wang F, Yang X, Zhang J, Wu H, Zhang Z, Zhang Z, He X, Zhou P, Wei Z et al. 2016 Biallelic SUN5 mutations cause autosomal-recessive acephalic spermatozoa syndrome. American Journal of Human Genetics 99 942-949. (doi:10.1016/j.ajhg.2016.08.004)
Zierhut C, Jenness C, Kimura H \& Funabiki H 2014 Nucleosomal regulation of chromatin composition and nuclear assembly revealed by histone depletion. Nature Structural and Molecular Biology 21 617-625. (doi:10.1016/j.ajhg.2016.08.004)

Received 21 December 2016

First decision 16 January 2017

Revised manuscript received 10 June 2017

Accepted 6 July 2017 